\title{
Exploration of Application of Integrated Teaching Mode in Marketing Course Teaching
}

\author{
Xiaolian Zhang \\ Jiangxi Environmental Engineering Vocational College, Ganzhou, 341000, China
}

Keywords: Integrated teaching, Teaching mode, Marketing, Teaching application.

\begin{abstract}
With the continuous improvement of China's economic development level and deep implementation of quality-oriented education, course teaching in colleges is gradually inclined to cultivate comprehensive talents with strong practical ability, knowledge ability and communication skills. Marketing course teaching develops under the impetus of market economy system and aims at cultivating social application-oriented, skill-oriented and practice-based talents, who need to command the fundamental marketing theories, command the latest modernized marketing concepts and have good market analysis ability, product development ability etc. For this reason, it is extremely important to achieve the above-mentioned objective of marketing course teaching by using the integrated teaching mode.
\end{abstract}

\section{Introduction}

Professor R • G • Havelock, a well-known educationalist, once defined "educational reform" and said: "teaching reform is a meaningful and functional conversion based on current situation of education." Similarly, in the outline of " $12^{\text {th }}$ Five-Year Plan", China also put forward the policy of "accelerating educational reform and development" and proposed to energetically develop vocational education and quality-oriented education, to accelerate the development of rural vocational education, to implement the cultivation mode of co-existence of engineering, university-enterprise cooperation and substituted post exercitation, thus to ceaselessly improve students' skills and occupational quality, strengthen the construction of "double-certificated" teachers and to energetically support the construction of practical training base of vocational education as well as skill training of secondary vocational schools. This paper is designed to optimize teaching mode, accelerate the exploration of "integrated" teaching mode, continuously enhance teaching atmosphere and increase the employment rate of students majoring in marketing during marking teaching in our country.

\section{Background of integrated teaching}

Integrated teaching, which refers to the process of adjusting and integrating teaching links, considers combined cultivation of students' vocational ability and practical ability as teaching content and uses methods of separately formulating teaching program and teaching plan to build a integrative training objective system and implement the whole teaching object by using various teaching links.

Since the establishment of New China, vocational technology has been developed rapidly; construction of vocational colleges has been continuously perfected and varieties of disciplines are also growing. However, with constant changes in market economy, vocational colleges cannot timely adjust their teaching modes so talents cultivated by them cannot adapt to the need of social and economic construction to hinder the stable and sustainable development of society and economy ${ }^{[1]}$. The major reasons are as follows: they don't have complete teaching thinking, philosophy and mode and still use the past traditional teaching methods so their talent cultivation fails to attain the expected 
goals. Based on the above background, it is required to change teaching modes to accelerate teaching reform in colleges and to constantly enhance teaching quality. Besides, integrated teaching can contribute to higher scientificity and timeliness of talent cultivation.

It is all-important to build an employment-oriented teaching system with occupational development as its teaching objective. Such integrated teaching can cause the following changes: namely, change from "knowledge transfer" to "knowledge processing and conversion" during teaching; change from "unitary-type" teaching to "behavior-guided" teaching; change from students' "passive acceptance" to "active learning"; change from "teaching at a fixed classroom" to "practice workshop as well as indoor and outdoor linkages" for teaching sites. Such changes in integrated teaching can result in a more open and practical teaching mode ${ }^{[2]}$.

\section{Significances of teaching mode with "integration of theories and practices"}

\section{The teaching mode with "integration of theories and practices" can manifest the features of vocational education}

Generally speaking, the teaching with "integration of theories and practices" is to set teaching contents combining both course theories and practical teaching, mutual combination of course teaching and skill operation, integrated allocation of practical training room, classroom and other teaching sites as well as integrated structural training of professional knowledge, skill operation and assessment of vocational skills. The design of such a teaching mode thoroughly broke the past derailment between theories and practical operations so that teaching links become concentrated. Besides, integrated teaching mode can give full play to teachers' guiding function so that teachers can set a teaching task consist with the teaching objective to provide students with framework guidance for their learning of professional knowledge and skills and teachers can give guidance and do practices simultaneously during interactions with students. This teaching mode can really realize the learning effect of "learning during teaching and applying during learning", stimulate students' learning enthusiasm, enhance students' ability of active learning, enrich practical links for classroom teaching and thus improve the teaching quality ${ }^{[3]}$. Under the guidance of such teaching links, teachers can make interconversions between theoretical knowledge and practical knowledge and alternately apply abstract thinking and visual perception so that students can have their thinking ability trained. Besides, students will be more impressed with knowledge learned under this mode with practices verifying theories. Without the sequence of learning theories first and then making practices or doing practices first and then learning theories, this teaching mode emphases learning in theories and theories in learning and the learning mode with "integration of theories and practices" so that students' theoretical knowledge and practical ability can be trained synchronously. "Integration with theories and practices" does not only lay stress on the importance of theoretical teaching, but emphasizes the effect of combined application of both theories and practices, really highlights the cultivation of students' operational ability and professional skills, sets up a spirit of innovation in vocational teaching and thus lay a foundation for students' future learning and vocational development.

\section{The teaching mode with "integration of theories and practices" can strengthen students' operating skills}

There are many weaknesses in the past teaching mode, which separate theoretical teaching from practical teaching, focuses on learning all theoretical knowledge first and then organizing concentrated practical teaching and is a product of current exam-oriented education, so it cannot meet the demands of development and innovation of vocational education. For this reason, implementation of teaching mode with the "integration of theories and practices" can reinforce the cognition of theories, is of great importance in the improvement of learning efficiency, increases the vividness, interestingness, researches and discussions in teaching by combining them both together, better mobilizes students' enthusiasm and deepens students' memory of theoretical knowledge. 
In addition, students can carry out skill operations in the training room, receive reinforced trainings from visual, listening, speaking and thinking aspects, say special professional vocabularies as they are trained in enterprises, get familiar with business procedures and combine their operational ability with their thinking skills so that both the teaching efficiency and teaching quality can be improved.

\section{The teaching mode with "integration of theories and practices" plays a positive role in construction of teacher staff}

As the implementation of teaching with "integration of theories and practices" needs teachers' coordination, teachers not only need to teach fundamental theoretical knowledge at class but also need to guide students' practical operations so that teachers can really have the "double-certificated" professional ability. Moreover, teachers can integrate enterprise training methods into their teaching philosophy, pay attention to updates of enterprises' skill training methods and enterprise culture and thus impart students with more novel knowledge. In addition, colleges also need to constantly organize teachers to accept professional trainings and carry out more academic conferences so that teachers from various fields can exchange their experience with each other, make up for their deficiencies in professional ability and practical teaching ability and really command the teaching method with the "integration of theories and practices" to provide supports for promoting the reform in integrated teaching.

\section{Current situation of application of teaching mode for marketing major}

At present, the planning and construction of practical training room, reform in specialized course, innovation in teaching methods etc. all show the characteristics of modernized vocational education during our college's active construction of vocational park and all of these are consistent with the characteristics of vocational education; besides, our college continuously accelerates investments in the construction of skill training room and multimedia classrooms so as to make authentic reforms in teaching mode and teaching method, realize integrations of teaching practice service, project teaching and behavior guidance etc. and to enhance teaching effects by combining the multimedia technology.

In the process of constant reforms in teaching mode, the promotion of teaching methods has aroused wide concern but there are still some difficulties in the implementation of teaching methods. Firstly, the implementation of traditional teaching methods requires the support of teaching sites and practical training bases; secondly, students' knowledge structure, learning basis and other aspects are largely different; many students spend most of their time in attending classes so they only have very limited time to do operations and thus their operational ability is far lower than their thinking ability. Students don't have high plasticity and lack interest in trying new things; there are insufficient teachers in colleges and most teachers lack teaching skills and experience because most of them accepted "college-to-college" cultivation of teachers; thus, such current year's graduates lack adequate teaching experience and don't have strong teaching practical ability ${ }^{[4]}$. During the implementation of integrated teaching, teachers need to coordinate, constantly update their concepts and have the abilities to analyze, understand and innovate in courses.

According to the characteristics of vocational education and teaching mentioned above, it is required to timely make reforms in teaching mode. The implementation of teaching mode needs to be centered on practical teaching links so that both vocational education and teaching quality are targeted at cultivation of talents and change the past teaching mode only relying on knowledge teaching into a innovative educational practice system. Thus, a quality supervision system in the mode of vocational education management can be formed to strengthen students' practical ability and consciousness of innovation.

\section{Application design of teaching mode with "integration of theories and practices" in marketing teaching}




\section{Compile course materials to adapt to the reform requirements of teaching mode}

Take the major of auto technology service \& marketing of a college as an example. The college's auto sales and auto after-sales reception are two primary major fields. For different marketing posts, their application of theoretical knowledge such as auto construction and auto culture is insufficient and it is required to meet the standard of professional ability. Skill applications such as customer reception, marketing planning and exhibition hall sales need to reach the effect of proficient skill application. For three-year majors, it is required to properly reduce theoretical knowledge teaching and continuously strengthen students' practical training. Based on course objective, teaching task, project and in combination with skill requirements of modularization and projectization, teachers can compile a set of teaching materials with "integration of theories and practices", which focus on high quality instead of large quantity in contents, pay attention to practicability and combine practical skills with professional knowledge to finally reinforce the specialized training.

\section{Design classroom by using the "task-driven method" and "grouping method" to manifest students' subjective role}

Teachers can understand the "task-driven method" based on emotion, knowledge and skills and make practice-based teaching tasks accordingly; besides, teachers need to focus on cultivating students' vocational ability, thinking ability and independent problem-solving ability so as to train students' comprehensive qualities. With teachers' positive guidance, students will independently solve all issues caught in learning to reinforce their self-confidence in learning. "Grouping method" means that students are divided into several groups for cooperative learning under the practical training objective set by teachers and finish their learning tasks with mutual assistances to attain the teaching objective ${ }^{[5]}$. For instance, auto sales work not only pays attention to students' language expression ability and ability to adapt themselves to changing circumstances, but also lays emphasis on cultivating individuals' executive capacity so that they can accomplish a business objective through mutual coordination of the team; when cooperating and communicating with others, they need to think from the customer's point of view. Students also need to solve such issues. Therefore, teachers need to use diversified teaching modes to train students' independent problem-solving ability to attain the objective of improving students' comprehensive qualities.

\section{Lay stress on the construction of evaluation system to make comprehensive and objective assessments on students}

Generally speaking, skills and theories are taught simultaneously in theoretical mode of integrated teaching, so students can make practical operation and learn theoretical knowledge synchronously to reach the effect of "applying what the learned". Under this circumstance, when assessing students, teachers need to combine theories with practices, consider practices as key points to help students understand the importance of practical operations in specialized course learning, indirectly reflect students' ability to comprehensively apply knowledge and give a more reasonable and comprehensive evaluation on students. An auto salesman, who has strong comprehensive abilities, not only needs to win customers' acceptance and comment of satisfaction for his work, but also needs to memorize all sorts of auto brands, command knowledge concerning auto maintenances etc. and consider them as assessment on vocational skills. In this way, the synchronization of practice, learning and assessment can be embodied and thus the course teaching can be more scientific and practical.

"Integration of theories and practices" is a new teaching mode. Its generation and development can be closely combined with skill training to further strengthen students' practical ability. Besides, it largely helps to construct the cultivation framework of professional qualities and skills and thus their own specialized teaching quality can be improved. Such a teaching mode with "integration of theories and practices" adopted by vocational colleges can always consider vocational development as their major work, find students' cognitive rules based on their learning characteristics, enhance concern on students' knowledge and skills, more focus on students' methods and channels to acquire knowledge and pay attention to the cultivation of students' view of life and values. Course reform should also 
focus on cultivating students' exploration ability, realize the combination of theories and practices, and attach importance to mutual permeation between skills and knowledge. When using the integrated teaching mode, teachers need to guide students to think more and make more operations and constantly improve the teaching process.

\section{Conclusion}

In brief, implementation of integrated teaching mode, which is an important means of current reform in quality-oriented education as well as an innovation and change in the past traditional teaching mode, plays an important role in the evolutionary process of course teaching. This paper chiefly analyzed and explored the background, significances, current situation and application design methods for the application of integrated teaching mode in marketing course teaching and thus showed that the implementation of integrated teaching can achieve more scientific and efficient course teaching.

\section{References}

[1] Wei Wentian. Application of teaching mode with "integration of teaching, learning and practice" in edible mushroom production technology course teaching in higher vocational education, Anhui Agricultural Sciences, 2013,41(3):1328-1329,1404.

[2] Xia Guixia, Shu Zongli and Xia Zhi et al. Construction and practice of integrated teaching mode in and out of class in public PE curriculum of Hubei University, Journal of Physical Education, 2010, 17 (2):73-77.

[3] Shi Xuefei and Xue Feng. Reform practice and study of teaching mode with "integration of engineering, production and learning" - taking "animation design and production" course as an example, China Educational Technology, 2013 (8): 104-109.

[4] Cheng Guilan, Cai Zhijun and Wang Zhenlong et al. Practice and exploration of cooperative learning under the teaching mode with integration of theories and practices in plant tissue culture technology course, Anhui Agricultural Sciences, 2012, 40 (22): 11514-11515,11522.

[5] Niu Zhihua. Construction of integrated teaching mode of "teaching, learning, practice and competition" to cultivate skilled talents majoring in music of higher vocational colleges, Education and Career, 2013 (27): 115-116. 